\title{
Maternal SNPs in the p53 pathway: Risk factors for trisomy 21 ?
}

\author{
Juliano André Boquett ${ }^{\mathrm{a}, \mathrm{b}, \mathrm{d}}$, Ana Paula Carneiro Brandalize ${ }^{\mathrm{a}, \mathrm{b}, \mathrm{c}}$, Lucas Rosa Fraga ${ }^{\mathrm{a}, \mathrm{b}, \mathrm{d}}$ and \\ Lavínia Schuler-Faccini ${ }^{\mathrm{a}, \mathrm{b}, \mathrm{c}, \mathrm{d}, *}$ \\ ${ }^{a}$ Departamento de Genética, Universidade Federal do Rio Grande do Sul, Porto Alegre, Brazil

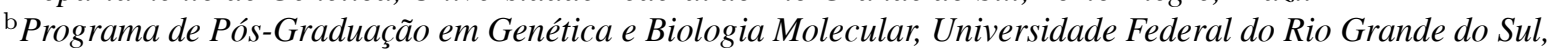 \\ Porto Alegre, Brazil \\ ${ }^{\mathrm{c}}$ Serviço de Genética Médica, Hospital de Clínicas de Porto Alegre, Porto Alegre, Brazil \\ ${ }^{\mathrm{d}}$ Instituto Nacional de Genética Médica Populacional - INAGEMP, Porto Alegre, Brazil
}

\begin{abstract}
The p53 family and its regulatory pathway play an important role as regulators of developmental processes, limiting the propagation of aneuploid cells. Its dysfunction or imbalance can lead to pathological abnormalities in humans. The aim of this study was to evaluate the effect of maternal polymorphisms TP53 c.215G $>$ C (P72R), TP73 4 c.-30G $>$ A and 14 c. $-20 \mathrm{C}>\mathrm{T}$, MDM2 c.14+309T>G (SNP309), MDM4 c.753+572C >T and USP7 c.2719-234G >A as risk factors for Down Syndrome (DS) birth. A case-control study was conducted with 263 mothers of DS children and 196 control mothers. The distribution of these genotypic variants was similar between case and control mothers. However, the combined alleles TP53 C and MDM2 G, and TP53 C and USP7 A increased the risk of having offspring with DS $(\mathrm{OR}=1.84$ and 1.77; 95\% CI; $P<0.007$ and 0.018 , respectively). These results suggest that, although the individual polymorphisms were not associated with DS birth, the effect of the combined genotypes among TP53, MDM2 and USP7 genes indicates a possible role of TP53 and its regulatory pathway as a risk factor for aneuploidy.
\end{abstract}

Keywords: Down syndrome, TP53, TP73, MDM2, MDM4, USP7

\section{Introduction}

Down Syndrome (DS), characterized by trisomy of chromosome 21 , is the most common cause of mental retardation in humans [23], occurring in 1 in 700800 births [30]. The meiotic nondisjunction is the main cause of free 21 trisomy, event responsible for the aneuploidy 21 in $95 \%$ of affected individuals [3]. In $95 \%$ of cases, the nondisjunction occurs during maternal meiosis [1], mainly in the first meiotic division [2,59]. It is well established that advanced maternal age is a risk factor for aneuploidy and is associated specifically with errors that occur during oogenesis [59].

Given the important role played by p53 family proteins as regulators of crucial developmental processes,

*Corresponding author: Lavínia Schuler-Faccini, Departamento de Genética, Universidade Federal do Rio Grande do Sul, Caixa Postal 15053, Agencia Campus UFRGS, CEP 91501-970/Porto Alegre RS, Brazil. Tel.: +51 33086726; Fax: +51 33598010; E-mail: lavinia.faccini@ufrgs.br. their dysfunction or imbalance can lead to pathological abnormalities in humans. Genomic instability, aneuploidy and copy number polymorphisms that originate in the female germline and contribute to a number of developmental defects can be explored through investigations of the TP53 gene family [26]. Encoded by TP53 gene, the p53 protein has known importance in the prevention of tumors and genomic stability in somatic cells, acting as a transcription factor that regulates a large number of genes in response to cell damage, including activation of oncogenes and DNA damage $[12,35,45]$. When activated, p53 initiates cellular responses, such as cell cycle arrest, DNA repair, senescence and apoptosis [22,27]. The loss of p53 allows the accumulation of aneuploid cells as a result of chromosomal instability. Thus, p53 and its regulatory pathway play a critical role in limiting the propagation of aneuploidy and preserving the nature of diploid human cells [55].

The central control of the p53 regulatory pathway consists of three major genes and their products: 
MDM2 (Mouse double minute p53 binding protein homolog 2), MDM4 (Mouse double minute p53 binding protein homolog 4) and USP7 (ubiquitin specific peptidase 7 (herpes virus-associated)), also known as HAUSP [10,29]. The main negative regulator of the TP53 is the protein MDM2, which acts on the p53 as an E3 ubiquitin ligase, leading to degradation of p53 [9, 31]. $M D M 2$ is upregulated by TP53, where the increase in 553 levels leads to increased transcription of $M D M 2$. Thus, the product degrades p53 by inhibiting their levels, resulting in a negative feedback loop. This process maintains the p53 protein at low level in the absence of stress signals, allowing normal cell proliferation [42, 47]. Participating in the same metabolic pathway, the TP73 gene plays a crucial role in maintaining the rate of ovulation and acting on the spindle checkpoint, reducing aneuploidy in the offspring [57]. p73 plays an important role in maintaining genomic integrity as well, which is particularly important when p53 function is compromised [5].

Single nucleotide polymorphisms (SNPs) in genes of the p53 regulatory pathway have been targeted for study in research relating to human reproduction [16, 17,29]. A common polymorphism in TP53 c. $215 \mathrm{G}>\mathrm{C}$ (P72R, rs1042522) [11], a substitution at codon 72 that makes the induction of apoptosis less efficient $[15,54]$. The $M D M 2$ gene has an important functional polymorphism c.14+309T>G (SNP309, rs2279744), the result of a thymine to guanine change in its promoter region [7], increasing $M D M 2$ expression and attenuating the 553 function $[7,16,29]$. A substitution in intron 9 of MDM4 gene c. $753+572 \mathrm{C}>\mathrm{T}(\mathrm{rs} 1563828)$ is correlated with human reproduction, as well as c.2719-234G $>\mathrm{A}$ change in intron 25 of USP7 gene (rs1529916) [29]. In $T P 73$, two closely linked polymorphisms in position 4 c. $-30 \mathrm{G}>\mathrm{A}$ and 14 c. $-20 \mathrm{C}>\mathrm{T}$ (rs2273953, rs1801173) are located before the initiating codon in exon 2 . This region can form a clamp-shaped structure with the potential to interfere in gene expression [28].

Thus, we hypothesized that polymorphisms related to TP53 and TP73 genes and genes in their regulatory pathway - MDM2, MDM4 and USP7 - may be closely associated with human reproduction, where its fine regulation is extremely important in maintaining genomic stability of germline cells avoiding aberrations in its genome, as aneuploidies. This study investigated the influence of the TP53 gene family and their regulators as risk factors for aneuploidy of chromosome 21. We analyzed the role of TP53 c. $215 \mathrm{G}>\mathrm{C}$ polymorphism (rs1042522), TP73 c.-30G $>$ A (rs2273953) and c. $-20 \mathrm{C}>\mathrm{T}$ (rs1801173), MDM2 c.14+309T>G (rs2279744), MDM4 c.753+572C>T (rs1563828) and USP7 c.2719-234G>A (rs1529916) as maternal risk factors for DS birth in a case-control study.

\section{Materials and methods}

\subsection{Subjects}

All cases were identified through Medical Genetic Service of Hospital de Clínicas de Porto Alegre (HCPA) and local support groups of DS (APAEs). The control group consisted of women with healthy children who were randomly selected to participate in this study during the blood collection for routine laboratorial analyzes in the HCPA. The case-control study was conducted with 263 case mothers and 196 control mothers. Further details on the selection and sample characteristics can be found in our previously published work [8].

This study was approved by the Ethics Committee of HCPA. All mothers who participated in the study signed an informed consent form. We collected $5 \mathrm{~mL}$ of peripheral blood in EDTA tubes for genetic analysis.

\subsection{Analysis of polymorphisms}

DNA was extracted from blood samples as described by Lahiri and Nurnberger [32]. The SNPs of five genes of the p53 signaling pathway were genotyped, including TP53, TP73, MDM2, MDM4 and USP7. Genotypes were determined by using the following allelic discrimination Taqman probes (Applied Biosystems): C_2403545_10 (TP53 gene), C_9493064_10 (MDM4 gene) and C_9688119_1 (USP7 gene). Since these two loci are closely linked, the genotype determination of polymorphisms c.-30G $>$ A (rs2273953) and c.-20C $>$ T (rs1801173) of TP73 gene was performed with the probe C_16180357_10 determining polymorphism c.30G $>$ A (rs2273953), a method previously used by Hamajima and colleagues (2002) [21] and Scacchi and colleagues (2009) [51]. To determine the genotype of $M D M 2$ gene c.14+309T $>\mathrm{G}$, probes were used which were labeled with FAM-TCCCGCGCCGCAG and VIC-CTCCCGCGCCGAAG fluorescence and primers forward 5' -CGGGAGTTCAGGGTAAAGGT3' and reverse 5'-ACAGGCACCTGCGATCATC-3'. The real-time PCR reactions were performed in 96 well plates in each reaction containing: $10 \mathrm{ng}$ of genomic DNA, 2x MasterMix Genotyping TaqMan (Applied Biosystems), probes specific for each polymorphism (40x) and enough water to reach $8 \mu \mathrm{L}$. The re- 
actions were conducted in the StepOnePlus ${ }^{\mathrm{TM}}$ PCR Real-Time System, with an initial cycle of 10 minutes at $95^{\circ} \mathrm{C}$, followed by 45 cycles at $95^{\circ} \mathrm{C}$ for $15 \mathrm{~s}$ and $63^{\circ} \mathrm{C}$ for 1 minute. The reactions for $\mathrm{c} .14+309 \mathrm{~T}>\mathrm{G}$ MDM2 gene were also conducted in 96 well plates in each reaction containing: 10ng of genomic DNA, 2x MasterMix Genotyping TaqMan (Applied Biosystems), $1 \mu \mathrm{M}$ of each primer and probe, and sufficient water to reach $25 \mu \mathrm{L}$. This reaction was also conducted in StepOnePlus ${ }^{\text {TM }}$ PCR Real-Time Systems, with the initial cycle of $2 \mathrm{~min}$ at $50^{\circ} \mathrm{C}$ for 10 minutes and heating at $95^{\circ} \mathrm{C}$, followed by 45 cycles at $95^{\circ} \mathrm{C}$ for $15 \mathrm{~s}$ and $60^{\circ} \mathrm{C}$ for 1 minute. The reaction products were analyzed on StepOne V2.2.2 Software.

\subsection{Statistical analysis}

Statistical analysis were performed using SPSS software, version 14.0. The chi-square was used to test the Hardy-Weinberg equilibrium, to compare allelic and genotypic frequencies, to compare the ethnicity, and the frequency of spontaneous abortions between groups. The gene-gene additive effect was also analyzed by chisquare test and logistic regression models were used to control the effect of maternal age at the time of conception. For maternal age, a dichotomous variable was used ( $<35$ or $\geqslant 35$ years) due to high prevalence of children with DS in women aged over 35 years, and $t$ test was performed to compare the mean maternal age. The ORs were used to quantify the association between each polymorphism and the risk of having a DS child. Using Epi-Info software version 6.0, we estimated to be able to detect an OR of 2.5 with a sample size of 150 cases and 150 controls with an assumed power of $80 \%$ and confidence level of 95\%. The Bonferroni's correction was applied for five tests in logistic regression analisys $\left(\alpha_{\text {Bonf }}=0.01\right)$.

\section{Results}

A total of 263 case mothers and 196 control mothers were studied. As expected, the mean maternal age was higher in case mothers (34.75 years \pm 8.05 vs. $28.26 \pm 5.99, P=0.000002)$ as well as the prevalence of mothers over 35 years of age in the case group (57\% vs. $20 \%, \mathrm{OR}=5.31,95 \% \mathrm{CI}=3.45-8.17, P<$ $0.000001)$ (6 missing values in control group). The case group contained $237(90.1 \%)$ mothers classified as Euro-descendants, 17 (6.5\%) as African-descent and $9(3.4 \%)$ classified as other ethnicity. In the control group, $175(89.7 \%)$ mothers were classified as Eurodescendants, $10(5.15 \%)$ as African-descent and 10 $(5.15 \%)$ as other ethnicity (1 missing value). The ethnic groups did not differ significantly between groups $(P=0.569)$. A higher frequency of spontaneous abortions was observed in the case group $(21.7 \%$ vs. $9.7 \%$, $P<0.001)$.

Table 1 shows the distribution of genotypes and allele frequencies of the studied polymorphisms between case and control groups, as well as in other european and euro-descendant populations. The allelic and genotypic frequencies of polymorphisms were in HardyWeinberg equilibrium and did not differ between case and control groups when analyzed separately, even when controlled for maternal age, ethnicity and spontaneous abortion. Our observed allele frequencies are in accordance to those described for euro-descendants.

The gene-gene additive effect was analyzed by a combination of TP53 risk allele with the risk alleles of other genes of its pathway (TP53 C and MDM2 G; TP53 C and MDM4 T; TP53 C and USP7 A; TP53 C and $T P 73 \mathrm{~A} / \mathrm{T})$. As shown in Table 2, the risk of having a child with DS in women with risk alleles for TP53 + MDM2 and TP53 + USP7 is 1.84 and 1.77 times higher, respectively (95\% CI and $P<0.007$ and 0.018 ), when adjusted for maternal age. We additionally tested the interaction of TP53, MDM2 and USP7 risk alleles together. The risk of having a DS child with this genotype is 2.04 higher $(95 \%$ IC and $P<0.020$ ) when controlled for maternal age. Interestingly, women under the age of 35 years at the time of conception showed a higher frequency of TP53 C allele associated with USP7 A allele $(\mathrm{OR}=1.99 ; 95 \% \mathrm{CI}=1.08-3.66 ; P<$ 0.026). When applying the Bonferroni's correction for multiple comparisons, the TP53/MDM2 additive effect maintained its statistical significance both in the unadjusted and in adjusted for maternal age model. However, the gene-gene additive effect including USP7 kept its significance only in the unadjusted analysis.

\section{Discussion}

Recent evidence has shown the important role played by $\mathrm{p} 53$ family as regulators of crucial processes related to human reproduction $[14,26]$. Our working hypothesis was based on two main pieces of evidence: 1) The loss of p53 function or genes that regulate this metabolic pathway may be related to the accumulation of aneuploid cells, increasing the risk of DS birth in women with these polymorphisms [55]. This same loss 
Table 1

Allelic and genotypic frequencies of SNPs in the TP53 pathway

\begin{tabular}{|c|c|c|c|c|c|c|}
\hline \multirow[t]{2}{*}{ Gene } & \multirow[t]{2}{*}{ Genotype/Allele } & \multirow[t]{2}{*}{ Case n $(\%)$} & \multirow[t]{2}{*}{ Control n (\%) } & \multirow[t]{2}{*}{$P^{*}$} & \multicolumn{2}{|c|}{ Expected allele frequency** } \\
\hline & & & & & 1000 Genomes [52] & HapMap [53] \\
\hline TP53 & GG & $116(44.1)$ & $99(50.5)$ & 0.322 & & \\
\hline \multirow[t]{3}{*}{ (rs1042522) } & GC & $123(46.8)$ & $78(39.8)$ & & & \\
\hline & $\mathrm{CC}$ & $24(9.1)$ & $19(9.7)$ & & & \\
\hline & $\mathrm{G}$ & $355(67.5)$ & $276(70.4)$ & 0.386 & 78.9 & 76.7 \\
\hline$M D M 2$ & $\mathrm{TT}$ & $104(39.5)$ & $82(41.9)$ & 0.442 & & \\
\hline \multirow[t]{3}{*}{ (rs2279744) } & TG & $123(46.8)$ & $81(41.3)$ & & & \\
\hline & GG & $36(13.7)$ & $33(16.8)$ & & & \\
\hline & $\mathrm{T}$ & $331(62.9)$ & $245(62.5)$ & 0.949 & 64.0 & NA \\
\hline MDM4 & $\mathrm{CC}$ & $88(33.5)$ & $70(35.7)$ & 0.832 & & \\
\hline \multirow[t]{3}{*}{ (rs1563828) } & CT & $124(47.1)$ & $87(44.4)$ & & & \\
\hline & TT & $51(19.4)$ & 39 (19.9) & & & \\
\hline & $\mathrm{C}$ & $300(57.0)$ & $227(57.9)$ & 0.843 & 67.9 & 65.0 \\
\hline USP7 & GG & $125(47.5)$ & $101(51.5)$ & 0.282 & & \\
\hline \multirow[t]{3}{*}{ (rs1529916) } & GA & $122(46.4)$ & $78(39.9)$ & & & \\
\hline & AA & $16(6.1)$ & $17(8.6)$ & & & \\
\hline & $\mathrm{G}$ & $372(70.7)$ & $280(71.4)$ & 0.873 & 67.3 & 68.9 \\
\hline$T P 73$ & $\mathrm{GG} / \mathrm{CC}$ & $161(61.2)$ & $109(55.6)$ & 0.381 & & \\
\hline \multirow[t]{3}{*}{ (rs2273953 and rs1801173) } & GA/CT & $87(33.1)$ & $71(36.2)$ & & & \\
\hline & $\mathrm{AA} / \mathrm{TT}$ & $15(5.7)$ & $16(8.2)$ & & & \\
\hline & $\mathrm{G} / \mathrm{C}$ & $409(77.8)$ & $289(73.7)$ & 0.181 & 79.9 & NA \\
\hline
\end{tabular}

${ }^{*}$ Chi-square; ${ }^{* *}$ Data from european and euro-descendants populations; NA $=$ not available.

Table 2

Risk allele combinations in the TP53 pathway

\begin{tabular}{lcccccc}
\hline Alleles $^{\dagger}$ & Case n (\%) & Control n (\%) & $P^{*}$ & OR (IC 95\%) & $P^{* *}$ & OR (IC 95\%) \\
\hline TP53C + MDM2G & $94(35.7)$ & $46(23.5)$ & 0.006 & $1.81(1.17-2.81)$ & 0.007 & $1.84(1.18-2.89)$ \\
TP53C + MDM4T & $96(36.5)$ & $65(33.2)$ & 0.521 & $1.16(0.77-1.74)$ & 0.536 & $1.14(0.75-1.74)$ \\
TP53C + USP7A & $80(30.4)$ & $37(18.9)$ & 0.007 & $1.88(1.18-3.00)$ & 0.018 & $1.77(1.10-2.85)$ \\
TP53C + TP73A/T & $58(22.0)$ & $43(21.9)$ & 0.933 & $1.01(0.63-1.61)$ & 0.760 & $1.08(0.66-1.75)$ \\
TP53 C + MDM2G + USP7A & $51(19.4)$ & $19(9.7)$ & 0.006 & $2.24(1.24-4.10)$ & 0.020 & $2.04(1.12-3.71)$ \\
\hline
\end{tabular}

${ }^{\dagger}$ Includes the presence of the allele in homozygosis or heterozygosis. ${ }^{*}$ Chi-square (Yates correction); ${ }^{* *} P$ and OR adjusted for maternal age by logistic regression.

of function could also decrease the action of apoptotic mechanisms that would eliminate aneuploid embryos in women with wild alleles [56]. Even if the inactivation of p53 is not the primary cause of aneuploidy, its dysfunction strongly facilitates a tolerance to this chromosomal instability [5] and, 2) Loss of p73 function due to polymorphisms in its encoding gene may interfere in the control of the meiotic spindle during oogenesis, increasing the risk of aneuploidy in the offspring [56,57]. The expression of TP73 naturally decreases with age, therefore the loss of TP73 function may contribute to the increase of aneuploidy produced by old oocytes $[26,56,57]$. In our sample about $43 \%$ of women were younger than 35 years at the time of the trisomic fetus conception. Thus, it becomes evident that mutations affecting the function of TP73 may be related to increased frequency of aneuploid pregnancies in young women. Supporting this hypothesis, a recent study showed that mice deficient in $\mathrm{p} 73$ presented spin- dle abnormalities, aneuploidy and little competence in fetal development [17].

The present study showed that polymorphisms in TP53, TP73, MDM2, MDM4 and USP7 genes do not represent a risk factor in the process of aneuploidy when analyzed separately, even when controlled for advanced maternal age. The distributions of allelic and genotypic frequencies found in this study are consistent with that expected for populations with European ancestry. Despite the ethnic admixture present in the Brazilian population, Southern Brazil has strong European ancestry, and the majority of our cases and controls were classified as Euro-descendants. This was confirmed by the similarity of allele frequencies observed in our sample compared to 1000 Genomes [52] and HapMap [53] databases for europeans and european-descendants.

Taking into account that the $\mathrm{p} 53$ pathway studied depends on multiple protein interactions, we found that the combination of TP53 and MDM2 polymorphisms, 
and possibly TP53 and USP7 contributes to this increased risk. The effect of TP53 $\mathrm{C}$ allele associated with USP7 A allele is probably maternal age independent as women under the age of 35 years at the time of conception showed a higher frequency of TP53 C allele associated with USP7 A allele. These results indicate a synergistic effect between genes that act in the same pathway in a multifactorial way. The allele P72 reduces the efficiency of p53 to induce apoptosis. Acting in the same signaling pathway, the $\mathrm{G}$ allele increases the expression of $M D M 2$, degrading more p53 and negatively influencing the induction of apoptosis in these cells [16]. Some studies showed that a large amount of $\mathrm{p} 53$ protein is produced by the human placenta in abnormal pregnancies. It is suspected that p53 is an important factor in the pathogenesis of diseases through the induction of throphoblast apoptosis [19,24, $37,48]$. Thus, the interaction of these polymorphisms could decrease the levels of the pro-apoptotic p53 protein, making it less functional in response to cell damage. As a consequence, the reaction would be attenuated by trophoblastic apoptosis and promote greater tolerance of aneuploidy.

Although these polymorphisms have never been investigated as possible risk factors for aneuploidy in humans, some studies showed an association between SNPs of p53 pathway and fertility, suggesting a specific role of p53 in the regulation of human reproduction. Pietrowski and colleagues (2005) [46] reported an association of the P72 allele and recurrent miscarriages. However, Fang and colleagues (2011) [16] did not find any difference in genotype and allele frequency of TP53 P72 and R72 forms through a case-control study involving women with miscarriages. They also reported that women with TP53 P72/P72 genotype and MDM2 G/G have a significantly higher expression of the $M D M 2$ protein, which may attenuate the response of apoptosis after DNA damage. The genes $M D M 2$, MDM4 and USP7, which produce proteins that regulate p53 level, had their minor alleles enriched in women seeking clinics for in vitro fertilization for the same SNPs studied [29,36].

The R72 and P72 forms of TP53 have different biological effects: R72 is more efficient in inducting apoptosis while P72 can promote a G1 arrest. This polymorphism seems to increase the chance of miscarriage in healthy women [46]. Thus, it is possible that genes that undergo selection in the TP53 pathway may affect human reproduction [29]. The G allele of MDM2 c.14+309T>G SNP is associated with a high risk of spontaneous abortion [16], which sup- ports the combined effect between this $M D M 2$ polymorphism and R72P of p53 [7,58]. The MDM4 gene, that is structurally homologous with the MDM2 gene, is also involved in the regulation of p53. The MDM4 protein indirectly affects p53, modulating its levels as well as $M D M 2$ activity [42], not only stimulating the ubiquitination of $\mathrm{p} 53$ mediated by $M D M 2$, but also the self-ubiquitination of $M D M 2$ [39]. The transcriptional activation of TP53 by MDM4 can be inhibited regardless of MDM2 [18], by binding to the TP53 transactivation domain, that contributes to the total inhibition of p53 [41]. The $\mathrm{T}$ allele of this polymorphism is associated with fertility in women, suggesting that MDM4 can regulate reproduction in a dependent and independent TP53 pathways, and may also interact with TP63 and TP73 [29]. Another important regulator of the p53 signaling pathway, the USP7 gene, acts in the stabilization of MDM2, MDM4 and p53 by deubiquitinating these proteins $[10,25,38]$. Other studies also reported an association of $T P 73$ polymorphisms with increased risk for Alzheimer's disease, leukoplakia and several types of cancer [40,43,51].

There are no functional studies regarding the polymorphism c.2719-234G >A of the USP7 gene. Kang and colleagues [29] found an association of the mutated A allele with infertility, showing the impact of this SNP on human fertility through the attenuation of the p53 pathway. As in this work, we also found a higher frequency of this allele in women younger than 35 years. The MDM2, MDM4 and USP7 proteins maintain the levels and activity of p53 that are critical to an appropriate transcriptional response signal after cell stress [29].

In humans, the p53 gene family appears to play other important roles in reproduction: TP53 is involved in the regulation of the blastocyst and $T P 73$ regulates the integrity of germ line cells [17]. Some evidence supports the involvement of p53 as functional in germline cells. Studies in C. elegans showed similar functions of that analogous to the p53 protein: cep-1 (C. elegans p53-like-1). During the development of germ cells cep1 ensures correct meiotic segregation [13]. In addition, the expression of CEP-1 at the end of pachytene, associated with the establishment of apoptotic competence, ensures that the germline cells with DNA damage or defects in meiotic recombination are eliminated before oogenesis. This process ensures that only healthy germ cells advance to the next generation [50]. Additionally, cks 2 proteins, that are essential components of cyclins complexes, and are involved in cell cycle control, have their expression negatively controlled by p53 at 
transcriptional and proteic level. This regulation contributes to control the transition from metaphase I to anaphase I in mammals' meiosis [49].

Despite the well established association between DS and advanced maternal age, the biochemical and molecular basis of nondisjunction are still not well understood. Altered patterns of recombination are known risks for nondisjunction [33,34]. More recently, Oliver and colleagues [44] have added support to the multifactorial etiology of nondisjunction in human meiosis. Their data suggested that pericentromeric chromatid exchanges during meiosis in females interact with maternal age-related risk factors, altering the susceptibility to nondisjunction. One year later, Gosh and colleagues [20] tested this hypotesis in an independent and ethnically different population in India and their results were consistent with those of Oliver and colleagues [44]. In our study we searched for different susceptibility factors that could predispose to aneuploidy, and we looked also for a possible interaction with advanced maternal age. However, a logistic regression considering maternal age failed to show an interaction between p53 pathway, maternal age and aneuploidy.

In this article we presented recent evidence linking the role of the TP53 family and its regulators in the maintenance spindle stability during meiosis and embryo development. Allied to this evidence and because of the lack of studies investigating the relationship of these polymorphisms with the genesis of aneuploidy in humans, this work is the first to establish a relationship between polymorphisms in the TP53 gene family and its regulatory pathway as a risk factor for aneuploidy of 21. Future studies in other populations should be conducted to confirm our findings, especially to clarify the factors independent of maternal age which may be involved in the development of aneuploid cells.

\section{Acknowledgments}

The authors acknowledge INAGEMP - National Institute of Population Medical Genetics (grant CNPq 573993/2008-4) for the support provided to this project.

\section{References}

[1] S.E. Antonarakis, Parental origin of the extra chromosome in trisomy 21 as indicated by analysis of DNA polymorphisms. Down Syndrome Collaborative Group, $N$ Engl J Med 324 (1991), 872-876.
[2] S.E. Antonarakis, M.B. Petersen, M.G. McInnis, P.A. Adelsberger, A.A. Schinzel, F. Binkert, C. Pangalos, O. Raoul, S.A. Slaugenhaupt, M. Hafez, M. M. Cohen, D. Roulson, S. Schwartz, M. Mikkelsenj, L. Tranebjaerg, F. Greenberg, D.I. Hoar, N.L. Rudd, A.C. Warren, C. Metaxotou, C. Bartsocas and A. Chakravarti, The meiotic stage of nondisjunction in trisomy 21: determination by using DNA polymorphisms, Am J Hum Genet 50 (1992), 544-550.

[3] S.E. Antonarakis, 10 years of Genomics, chromosome 21, and Down syndrome, Genomics 51 (1998), 1-16.

[4] G.S. Atwal, G.L. Bond, S. Metsuyanim, M. Papa, E. Friedman, T. Distelman-Menachem, E. Ben Asher, D. Lancet, D.A. Ross, J. Sninsky, T.J. White, A.J. Levine and R. Yarden, Haplotype structure and selection of the MDM2 oncogene in humans, Proc Natl Acad Sci USA 104 (2007), 4524-4529.

[5] Y. Aylon, M. Oren, p53: guardian of ploidy, Mol Oncol 5 (2011), 315-23.

[6] G. Beckman, R. Birgander, A. Själander, N. Saha, P.A. Holmberg, A. Kivelä and L. Beckman, Is p53 polymorphism maintained by natural selection? Hum Hered 44 (1994), 266-270.

[7] G.L. Bond, W. Hu, E.E. Bond, H. Robins, S.G. Lutzker, N.C. Arva, J. Bargonetti, F. Bartel, H. Taubert, P. Wuerl, K. Onel, L. Yip, S.J. Hwang, L.C. Strong, G. Lozano and A.J Levine, A single nucleotide polymorphism in the MDM2 promoter attenuates the p53 tumor suppressor pathway and accelerates tumor formation in humans, Cell 119 (2004), 591-602.

[8] A.P.C. Brandalize, E. Bandinelli, P.A. dos Santos, I. Roisenberg and L. Schüler-Faccini, Evaluation of C677T and A1298C polymorphisms of the MTHFR gene as maternal risk factors for Down syndrome and congenital heart defects, $\mathrm{Am}$ J Med Genet 149A (2009), 2080-2087.

[9] C.L. Brooks and W. Gu, p53 ubiquitination: Mdm2 and beyond, Mol Cell 21 (2006), 307-315.

[10] C.L. Brooks, M. Li, M. Hu, Y. Shi and W. Gu, The p53-Mdm2HAUSP complex is involved in p53 stabilization by HAUSP, Oncogene 26 (2007), 7262-7266.

[11] V.L. Buchman, P.M. Chumakov, N.N. Ninkina, O.P. Samarina and G.P. Georgiev, A variation in the structure of the proteincoding region of the human p53 gene, Gene 70 (1988), 245252.

[12] A.N. Bullock and A.R. Fersht, Rescuing the function of mutant p53, Nature Rev Cancer 1 (2001), 68-76.

[13] W.B. Derry, A.P. Putzke and J.H. Rothman, Caenorhabditis elegans p53: Role in apoptosis, meiosis, and stress resistance, Science 294 (2001) 591-595.

[14] V. Dötsch, F. Bernassola, D. Coutandin, E. Candi and G. Melino, p63 and p73, the ancestors of p53, Cold Spring Harb Perspect Biol 2 (2010), a004887.

[15] P. Dumont, J.I. Leu, A.C. Della Pietra 3rd, D.L. George and M. Murphy, The codon 72 polymorphic variants of $\mathrm{p} 53$ have markedly different apoptotic potential, Nat Genet 33 (2003), 357-365.

[16] Y. Fang, B. Kong, Q. Yang, D. Ma and X. Qu, The p53HDM2 gene-gene polymorphism interaction is associated with the development of missed abortion, Hum Reprod 26 (2011), 1252-1258.

[17] Z. Feng, C. Zhang, H.J. Kang, Y. Sun, H. Wang, A. Naqvi, A.K. Frank, Z. Rosenwaks, M.E. Murphy, A.J. Levine and W. $\mathrm{Hu}$, Regulation of female reproduction by $\mathrm{p} 53$ and its family members, FASEB J 25 (2011), 2245-2255.

[18] S. Francoz, P. Froment, S. Bogaerts, S. De Clercq, M. Maetens, G. Doumont, E. Bellefroid and J.C. Marine, Mdm4 and Mdm2 cooperate to inhibit p53 activity in proliferating and quiescent cells in vivo, Proc Natl Acad Sci USA 103 (2006), 3232-3237. 
[19] V. Fulop, S.C. Mok, D.R. Genest, I. Szigetvari, I. Cseh and R.S. Berkowitz, c-myc, c-erbB-2, c-fms and bcl-2 oncoproteins: expression in normal placenta, partial and complete mole, and choriocarcinoma, J Reprod Med 43 (1998), 101110.

[20] S. Ghosh, E. Feingold and S.K. Dey, Etiology of Down syndrome: Evidence for consistent association among altered meiotic recombination, nondisjunction, and maternal age across populations, Am J Med Genet A 149A (2009), 14151420.

[21] N. Hamajima, K. Matsuo, T. Suzuki, T. Nakamurab, A. Matsuurab, S. Hatookac, M. Shinodac, Y. Koderac, Y. Yamamurac, T. Hirai, T. Kato and K. Tajima, No association of p73 G4C14-to-A4T14 at exon 2 and p53 Arg72Pro polymorphism with the risk of digestive tract cancers in Japanese, Cancer Lett 181 (2002), 81-85.

[22] S.L. Harris and A.J. Levine, The p53 pathway: Positive and negative feedback loops, Oncogene 24 (2005), 2899-2908.

[23] T. Hassold and P. Jacobs, Trisomy in man, Ann Rev Genet 18 (1984), 69-97.

[24] C. Hu, S.D. Smith, L. Pang, Y. Sadovsky and D.M. Nelson, Enhanced basal apoptosis in cultured term human cytotrophoblasts is associated with a higher expression and physical interaction of p53 and Bak, Placenta 27 (2006), 978-983.

[25] M. Hu, L. Gu, M. Li, P.D. Jeffrey, W. Gu and Y. Shi, Structural basis of competitive recognition of p53 and MDM2 by HAUSP/USP7: implications for the regulation of the p53MDM2 pathway, PLoS Biol 4 (2006), e27.

[26] W. Hu, The role of p53 gene family in reproduction, Cold Spring Harb Perspect Biol 1 (2009), a001073.

[27] S. Jin and A.J. Levine, The p53 functional circuit, $J$ cell sci 114 (2001), 4139-4140.

[28] M. Kaghad, H. Bonnet, A. Yang, L. Creancier, J.C. Biscan, A. Valent, A. Minty, P. Chalon, J.M. Lelias, X. Dumont, P. Ferrara, F. McKeon and D. Caput, Monoallelically expressed gene related to $\mathrm{p} 53$ at $1 \mathrm{p} 36$, a region frequently deleted in neuroblastoma and other human cancers, Cell 90 (1997), 809 819.

[29] H.J. Kang, Z. Feng, Y. Sun, G. Atwal, M.E. Murphy, T.R. Rebbeck, Z. Rosenwaks, A.J. Levine and W. Hu, Singlenucleotide polymorphisms in the p53 pathway regulate fertility in humans, Proc Natl Acad Sci USA 106 (2009), 9761-9766.

[30] E. Krivchenia, C.A. Huether, L.D. Edmonds, D.S. May and S. Guckenberger, Comparative epidemiology of Down syndrome in two United States populations, Am J Epidemiol 137 (1993), 815-828.

[31] P.H. Kussie, S. Gorina, V. Marechal, B. Elenbaas, J. Moreau, A.J. Levine and N.P. Pavletich, Structure of the MDM2 oncoprotein bound to the p53 tumor suppressor transactivation domain, Science 274 (1996), 948-953.

[32] D.K. Lahiri and J.I. Nurnberger, Jr., A rapid non-enzymatic method for the preparation of HMW DNA from blood for RFLP studies, Nucleic Acids Res 19 (1991) 5444.

[33] N.E. Lamb, S.B. Freeman, A. Savage-Austin, D. Pettay and L. Taft, Susceptible chiasma configurations of chromosome 21 predispose to nondisjunction in both maternal meiosis I and meiosis II, Nat Genet 14 (1996), 400-405.

[34] N.E. Lamb, E. Feingold, A. Savage, D. Avramopoulos and S. Freeman, Characterization of susceptible chiasma configurations that increase the risk for maternal nondisjunction of chromosome 21, Hum Mol Genet 6 (1997), 1391-1399.

[35] A.J. Levine, W. Hu and Z. Feng, The P53 pathway: What questions remain to be explored, Cell Death Differ 13 (2006), 1027-1036.
[36] A.J. Levine, R. Tomasini, F.D. McKeon, T.W. Mak and G. Melino, The p53 family: Guardians of maternal reproduction, Nat Rev Mol Cell Biol 4 (2011), 259-265.

[37] R. Levy, S.D. Smith, K. Yusuf, P.C. Huettner, F.T. Kraus and Y. Sadovsky, Trophoblast apoptosis from pregnancies complicated by fetal growth restriction is associated with enhanced p53 expression, Am J Obstet Gynecol 186 (2002), 1056-1061.

[38] M. Li, D. Chen, A. Shiloh, J. Luo, A.Y. Nikolaev, J. Qin and W. Gu, Deubiquitination of 553 by HAUSP is an important pathway for p53 stabilization, Nature 416 (2002), 648-653.

[39] L.K. Linares, A. Hengstermann, A. Ciechanover, S. Müller and M. Scheffner, HdmX stimulates Hdm2-mediated ubiquitination and degradation of p53, Proc Natl Acad Sci USA 100 (2003), 12009-12014.

[40] F. Liu, L. Liu, B. Li, Y.G. Wei, L.N. Yan, T.F. Wen, M.Q. Xu, W.T. Wang and J.Y. Yang, p73 G4C14-A4T14 polymorphism and cancer risk: A meta-analysis based on 27 case-control studies, Mutagenesis 26 (2011), 573-581.

[41] J.-C. Marine and A.G. Jochemsen, Mdmx as an essential regulator of p53 activity, Biochem Biophys Res Commun 331 (2005), 750-760.

[42] J.-C. Marine, S. Francoz, M. Maetens, G. Wahl, F. Toledo and G. Lozano, Keeping p53 in check: essential and synergistic functions of Mdm2 and Mdm4, Cell Death Differ 13 (2006), 927-934.

[43] C. Misra, M. Majumder, S. Bajaj, S. Ghosh, B. Roy and S. Roychoudhuryet, Polymorphisms at p53, p73, and MDM2 Loci Modulate the Risk of Tobacco Associated Leukoplakia and Oral Cancer, Molecular Carcinogenesis 48 (2009), 790800.

[44] T.R. Oliver, E. Feingold, K. Yu, V. Cheung, S. Tinker, M. Yadav-Shah, N. Masse and S.L. Sherman, New insights into human nondisjunction of chromosome 21 in oocytes, PLoS Genet. 4 (2008): e1000033.

[45] M. Oren, Decision making by p53: life, death and cancer, Cell Death Differ 10 (2003), 431-442.

[46] D. Pietrowski, H. Bettendorf, E.K. Riener, C. Keck, L.A. Hefler, J.C. Huber and C. Tempfer, Recurrent pregnancy failure is associated with a polymorphism in the p53 tumor suppressor gene, Hum Reprod 4 (2005), 848-851.

[47] C. J. Proctor and D.A. Gray, Explaining oscillations and variability in the p53-Mdm2 system, BMC Syst Biol 2 (2008), 75.

[48] S. Qiao, T. Nagasaka, T. Harada and N. Nakashima, p53, Bax and $\mathrm{Bcl}-2$ expression, and apoptosis in gestational trophoblast of complete hydatidiform mole, Placenta 19 (1998), 361-369.

[49] K. Rother, M. Dengl, J. Lorenz, K. Tschöp, R. Kirschner, J. Mössner and K. Engeland, Gene expression of cyclindependent kinase subunit Cks2 is repressed by the tumor suppressor $\mathrm{p} 53$ but not by the related proteins $\mathrm{p} 63$ or $\mathrm{p} 73$, FEBS Lett 581 (2007), 1166-1172.

[50] R. Rutkowski, R. Dickinson, G. Stewart, A. Craig, M. Schimpl, S.M. Keyse and A. Gartner, Regulation of Caenorhabditis elegans p53/CEP-1-dependent germ cell apoptosis by Ras/MAPKsignaling, PLoS Genet 7 (2011): e1002238.

[51] R. Scacchi, G. Gambina, G. Moretto and R.M. Corbo, Association study between P53 and P73 gene polymorphisms and the sporadic late-onset form of Alzheimer's disease, J Neural Transm 116 (2009), 1179-1184.

[52] The 1000 Genomes Project Consortium, A map of human genome variation from population-scale sequencing, Nature 467 (2010), 1061-1073.

[53] The International HapMap Consortium, Integrating common 
and rare genetic variation in diverse human populations, $\mathrm{Na}$ ture 467 (2010), 52-58.

[54] M. Thomas, A. Kalita, S. Labrecque, D. Pim, L. Banks and G. Matlashewski, Two polymorphic variants of wild-type p53 differ biochemically and biologically, Mol Cell Biol 19 (1999), 1092-1100.

[55] S.L. Thompson and D.A. Compton, Proliferation of aneuploid human cells is limited by a p53-dependent mechanism, J Cell Biol 188 (2010), 369-81.

[56] R. Tomasini, K. Tsuchihara, M. Wilhelm, M. Fujitani, A. Rufini, C.C. Cheung, F. Khan, A. Itie-Youten, A. Wakeham, M.S. Tsao, J.L. Iovanna, J. Squire, I. Jurisica, D. Kaplan, G. Melino, A. Jurisicova and T.W. Mak, TAp73 knockout shows genomic instability with infertility and tumor suppressor functions, Genes Dev 22 (2008), 2677-2691.
[57] R. Tomasini, K. Tsuchihara, C. Tsuda, S.K. Lau, M. Wilhelm, A. Ruffini, M.S. Tsao, J.L. Iovanna, A. Jurisicova, G. Melino and T.W. Mak, TAp73 regulates the spindle assembly checkpoint by modulating BubR1 activity, Proc Natl Acad Sci USA 106 (2009), 797-802.

[58] Y. Wan, W. Wu, Z. Yin, P. Guan and B. Zhou, MDM2 SNP309, gene-gene interaction, and tumor susceptibility: An updated meta-analysis, BMC Cancer 11 (2011), 208.

[59] P.W. Yoon, S.B. Freeman, S.L. Sherman, L.F. Taft, Y. Gu, D. Pettay, W.D. Flanders, M.J. Khoury and T.J. Hassold, Advanced maternal age and the risk of Down syndrome characterized by the meiotic stage of chromosomal error: A populationbased study, Am J Hum Genet 58 (1996), 628-633. 


\section{Supplementary material}

Table $\mathrm{S} 1$

Allelic and genotypic frequencies of SNPs in the TP53 pathway in euro-descendants

\begin{tabular}{|c|c|c|c|c|c|c|}
\hline \multirow[t]{2}{*}{ Gene } & \multirow[t]{2}{*}{ Genotype/Allele } & \multirow[t]{2}{*}{ Case n $(\%)$} & \multirow[t]{2}{*}{ Control n (\%) } & \multirow[t]{2}{*}{$P *$} & \multicolumn{2}{|c|}{ Expected allele frequency** } \\
\hline & & & & & 1000genomes [52] & HapMap [53] \\
\hline TP53 & GG & $106(44.7)$ & $92(52.6)$ & 0.164 & & \\
\hline \multirow[t]{3}{*}{ (rs1042522) } & GC & $113(47.7)$ & $67(38.3)$ & & & \\
\hline & $\mathrm{CC}$ & $18(7.6)$ & $16(9.1)$ & & & \\
\hline & G & $325(68.6)$ & $251(71.7)$ & 0.369 & 78.9 & 76.7 \\
\hline$M D M 2$ & TT & $96(40.5)$ & 75 (42.9) & 0.666 & & \\
\hline \multirow[t]{3}{*}{ (rs2279744) } & TG & $109(46.0)$ & $73(41.7)$ & & & \\
\hline & GG & $32(13.5)$ & $27(15.4)$ & & & \\
\hline & $\mathrm{T}$ & $301(63.5)$ & $223(63.7)$ & 0.991 & 64.0 & NA \\
\hline MDM4 & $\mathrm{CC}$ & $83(35.0)$ & $63(36.0)$ & 0.978 & & \\
\hline \multirow[t]{3}{*}{ (rs1563828) } & $\mathrm{CT}$ & $111(46.8)$ & $81(42.3)$ & & & \\
\hline & TT & $43(18.2)$ & $31(17.7)$ & & & \\
\hline & $\mathrm{C}$ & $277(58.4)$ & $207(59.1)$ & 0.895 & 67.9 & 65.0 \\
\hline USP7 & GG & $111(46.8)$ & 87 (49.7) & 0.482 & & \\
\hline \multirow[t]{3}{*}{ (rs1529916) } & GA & $111(46.8)$ & $73(41.7)$ & & & \\
\hline & AA & $15(6.4)$ & $15(8.6)$ & & & \\
\hline & G & $333(70.3)$ & $247(70.6)$ & 0.982 & 67.3 & 68.9 \\
\hline TP73 & GG/CC & $149(62.9)$ & $98(56.0)$ & 0.269 & & \\
\hline \multirow[t]{3}{*}{ (rs2273953 and rs1801173) } & GA/CT & $76(32.0)$ & $63(36.0)$ & & & \\
\hline & $\mathrm{AA} / \mathrm{TT}$ & $12(5.1)$ & $14(8.0)$ & & & \\
\hline & $\mathrm{G} / \mathrm{C}$ & $374(78.9)$ & $259(74.0)$ & 0.117 & 79.9 & NA \\
\hline
\end{tabular}

${ }^{*}$ Chi-square; ${ }^{* *}$ Data from european and euro-descendants populations. NA $=$ not available.

Table S2

Risk allele combinations in the TP53 pathway showing data for euro-descendants only

\begin{tabular}{|c|c|c|c|c|c|c|}
\hline Alleles $^{\dagger}$ & Case n $(\%)$ & Control n $(\%)$ & $P^{*}$ & OR (IC 95\%) & $P^{* *}$ & OR $(\mathrm{IC} 95 \%)^{* *}$ \\
\hline$T P 53 \mathrm{C}+M D M 2 \mathrm{G}$ & $82(34.6)$ & $38(21.7)$ & 0.006 & $1.91(1.19-3.06)$ & 0.009 & $1.90(1.17-3.06)$ \\
\hline$T P 53 \mathrm{C}+M D M 4 \mathrm{~T}$ & $82(34.6)$ & $55(31.4)$ & 0.569 & $1.15(0.75-1.79)$ & 0.551 & $1.14(0.73-1.79)$ \\
\hline$T P 53 \mathrm{C}+U S P 7 \mathrm{~A}$ & $72(30.4)$ & $32(18.3)$ & 0.007 & $1.95(1.19-3.22)$ & 0.016 & $1.85(1.12-3.06)$ \\
\hline$T P 53 \mathrm{C}+T P 73 \mathrm{~A} / \mathrm{T}$ & $50(21.1)$ & $34(19.4)$ & 0.770 & $1.11(0.66-1.86)$ & 0.502 & $1.19(0.71-2.02)$ \\
\hline$T P 53 \mathrm{C}+M D M 2 \mathrm{G}+U S P 7 \mathrm{~A}$ & $45(19.0)$ & $15(8.6)$ & 0.005 & $2.50(1.29-4.88)$ & 0.016 & $2.23(1.16-4.60)$ \\
\hline
\end{tabular}

$\dagger$ Includes the presence of the allele in homozygosis or heterozygosis. ${ }^{*}$ Chi-square (Yates correction). ${ }^{* *} P$ and OR adjusted for maternal age by logistic regression. 


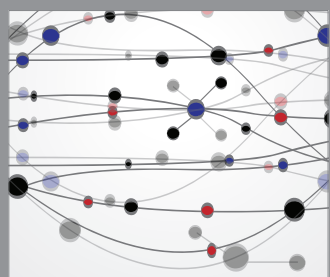

The Scientific World Journal
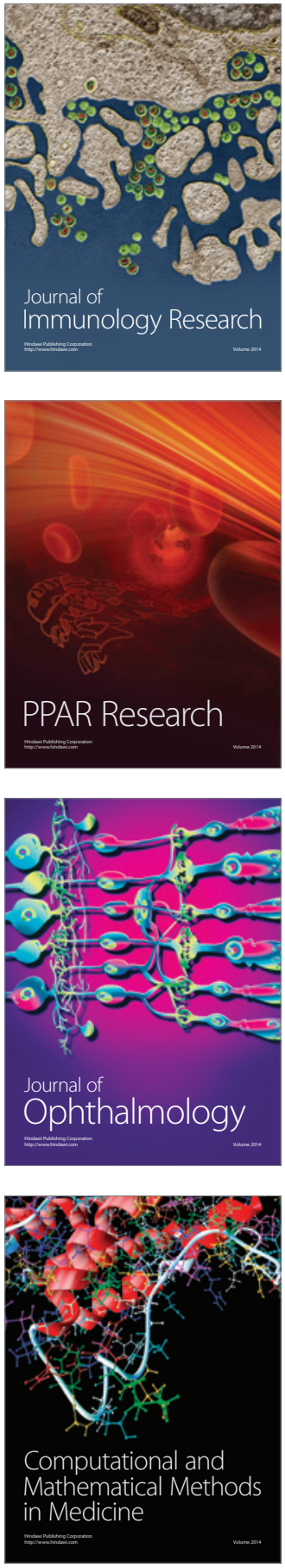

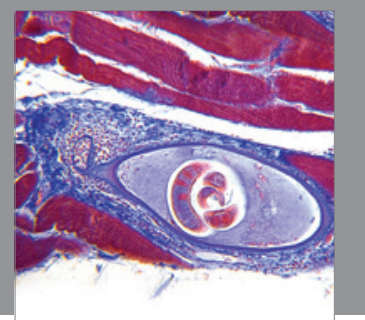

Gastroenterology

Research and Practice
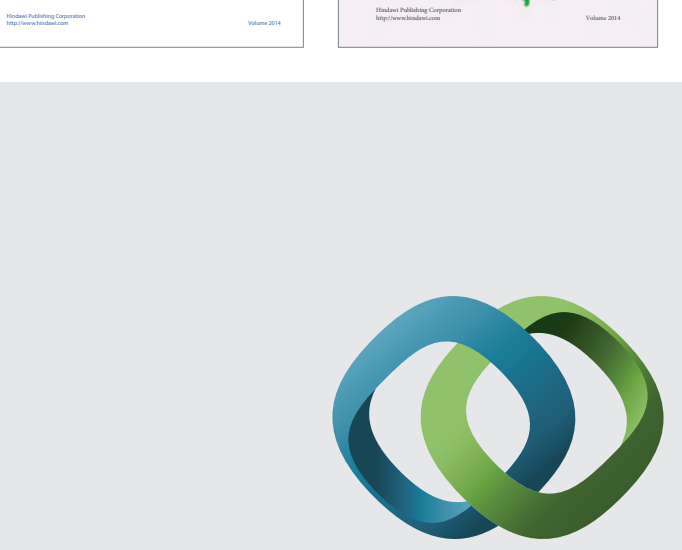

\section{Hindawi}

Submit your manuscripts at

http://www.hindawi.com
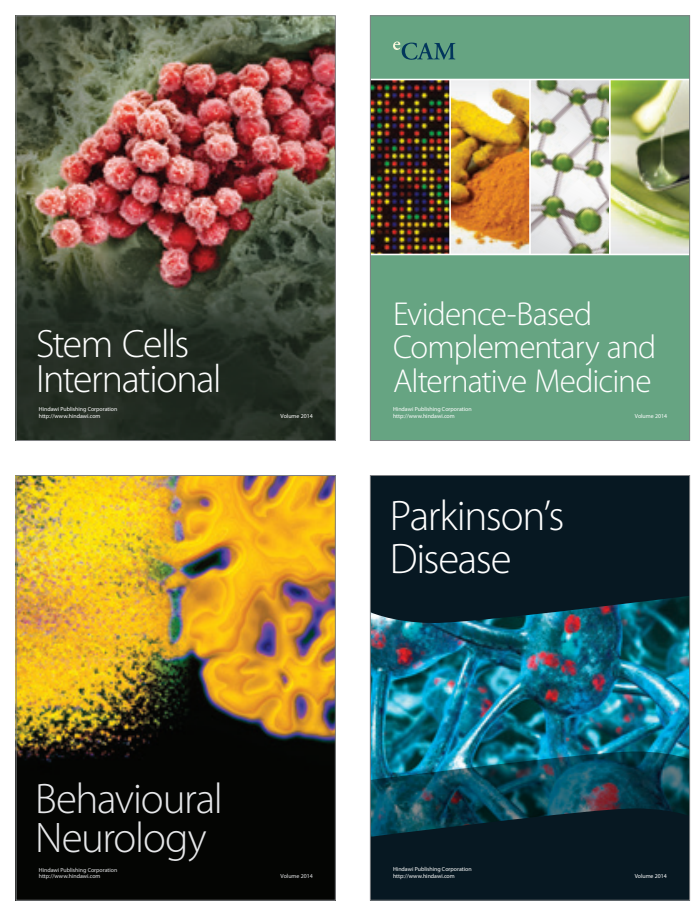

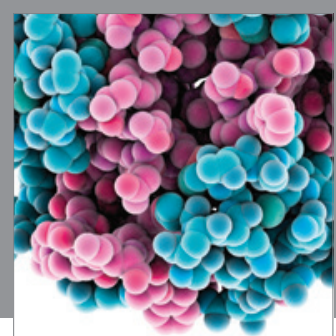

Journal of
Diabetes Research

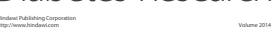

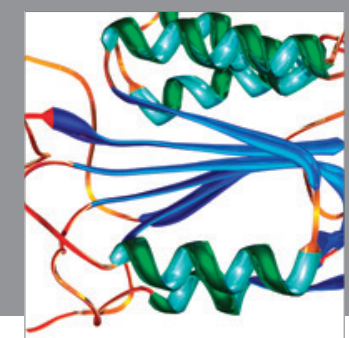

Disease Markers
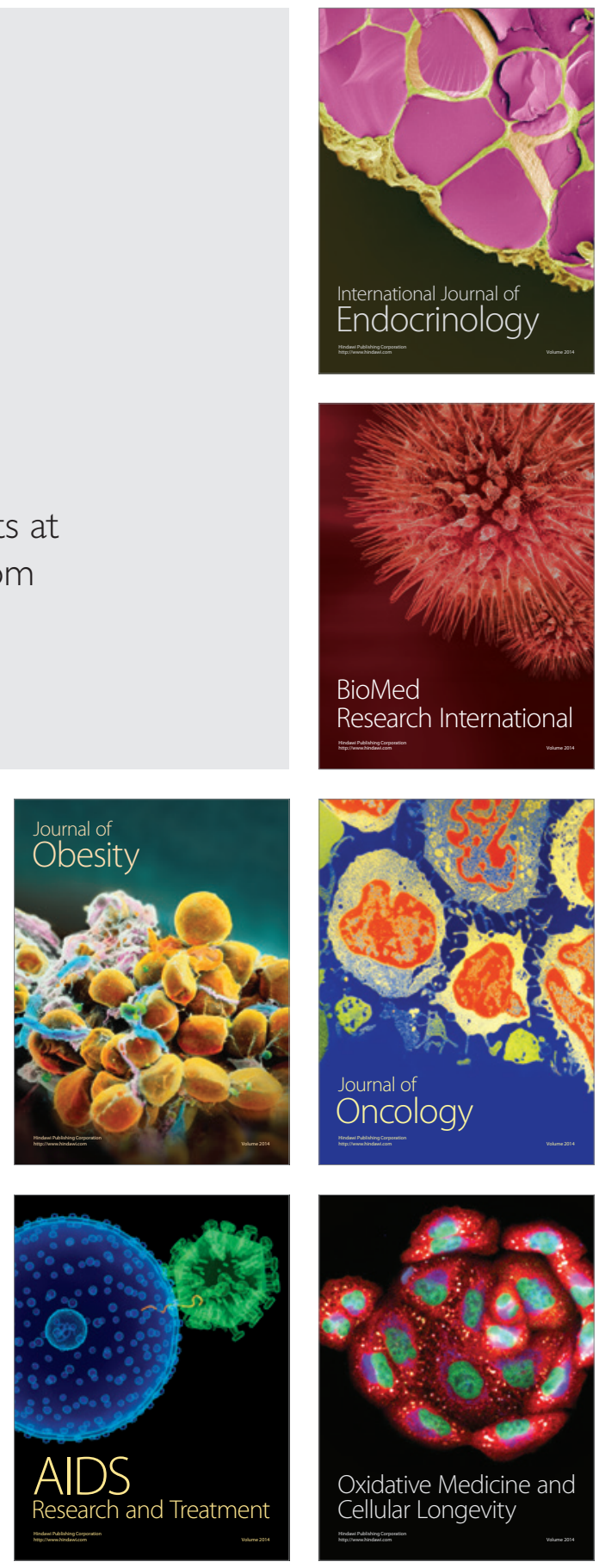